SHORT COMMUNICATION

Sokoto Journal of Veterinary Sciences

(P-ISSN 1595-093X: E-ISSN 2315-6201)

http://dx.doi.org/10.4314/sokjvs.v17i2.10

Oziegbe et al./Sokoto Journal of Veterinary Sciences, 17(2): 69 - 72.

\title{
The different traditional pre-slaughter handling methods for dogs at Jos south Local Government Area of Plateau State, Nigeria
}

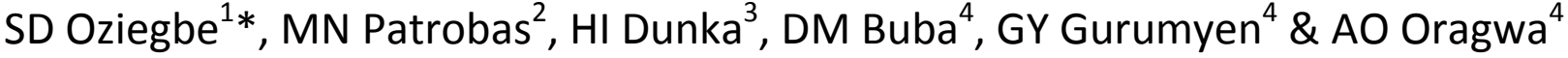 \\ 1. Department of Theriogenology and Production, Faculty of Veterinary Medicine, University of Jos. \\ Plateau State, Nigeria \\ 2. Department of Veterinary Parasitology and Entomology, Faculty of Veterinary Medicine, \\ University of Jos, Plateau State, Nigeria \\ 3. Department of Veterinary Public Health and Preventive Medicine, Faculty of Veterinary Medicine, \\ University of Jos, Plateau State, Nigeria \\ 4. Department of Veterinary Microbiology and Pathology, Faculty Veterinary Medicine, University of \\ Jos Plateau State Nigeria
}

*Correspondence: Tel.: +2348037000189; E-mail: ozigbestanley@gmail.com

\begin{abstract}
Copyright: (C) 2019 Oziegbe et al. This is an open-access article published under the terms of the Creative Commons Attribution License which permits unrestricted use, distribution, and reproduction in any medium, provided the original author and source are credited.

Abstract

The consumption of dog meat has been reported in many countries of the world including Nigeria. Different pre-slaughter handling methods are commonly used prior to dog slaughter in many parts of the country including Plateau State. This study determined the frequency and reasons for the use of the various traditional preslaughter handling methods at the "Angwan Kare" Dog Market Jos. Relevant data were collected from 120 butchers interviewed randomly in groups of 20 for six consecutive days. The data obtained were analyzed using descriptive statistics. A total of 120 butchers were interviewed, 114 (95\%) used the strangulation method of preslaughter handling. The suffocation method was used by 2 butchers with $1.7 \%$ as the overall use frequency. The stunning method was used by 4 butchers with $3.3 \%$ as the overall frequency of use. It is evident from this study that the strangulation method with frequency of $95 \%$ is the most used of the pre-slaughter handling methods. Dog

Publication History: Received: $17-11-2018$ butchers should be trained and taught proper pre-slaughter stunning techniques to enhance meat quality and dog welfare through the relief of pain, fear and suffering.
\end{abstract} Accepted:01-03-2019

Keywords: Dog, Frequency, Handling, Market, Pre-slaughter

\section{Introduction}

The slaughter and consumption of dog meat has been reported in many countries of the world. These include China, Mexico, Rome, South Korea (Rupert, 2002); India, Indonesia, (Mao, 2010; Shepherd, 2012), Cameroon, Ghana and Nigeria (Simmons, 1994). Dogs in Nigeria are used for myriad of purposes, such as hunting, guarding, for income, as pets, and source of meat (Aiyedun \& Olugasa, 2012). It is the mixed-breed dog (Mongrel) that is commonly slaughtered for meat in Nigeria. Dog meat is relished by some tribes and ethnic groups in States such as Cross River, Akwa Ibom, Ondo, Ekiti, 
Kaduna, Plateau, Gombe, Adamawa, Edo and Abia (Ehimiyein et al., 2014). The meat is eaten for several reasons, some of which include ritual or ceremonial purposes (Michele, 2017); as a delicacy (Mao, 2010); source of food in times of war (Douglas, 2009) and as well for its medicinal values (Murray, 2007).

The concern for animal welfare is now a major consideration in meat production based on the belief that animals can suffer (Manteca, 1998). Dogs are slaughtered traditionally using different preslaughter handling methods. These include strangulation of dogs through the use of motorcycle clutch cable wires, they can be forced into sacks and beaten with large sticks, iron rods and left to suffocate to death (Ehimiyein et al., 2014). In few instances, stunning is performed using local wooden staffs, which often does not deliver the required blow power for proper stunning prior to slaughter. These traditional pre-slaughter handling methods coupled with the belief that the more gruesome the death of a dog the better the meat quality (Elisha \& Solomon, 2008) are certainly not humane. The aim of this study is to determine the frequency and reasons for the use of these different traditional preslaughter handling methods among dog butchers at the "Angwan Kare" dog market Jos, Nigeria.

\section{Materials and Methods}

The study was conducted at the local dog market "Angwan Kare" situated at Jos South Local Government Area of Plateau State, Nigeria. Dogs are usually sold and slaughtered for meat in the market. A total of 120 butchers were interviewed randomly by the oral method for six days, twenty butchers per group were interviewed daily for the period. The question was to know the traditional pre-slaughter handling methods used by each of them prior to dog slaughter and the reasons for such preference.
Data were obtained from interviews conducted on 120 dog butchers on the traditional pre- slaughter handling methods used by them prior to the slaughter of dogs. Data from the survey showed that the butchers used the strangulation, suffocation and the stunning methods of pre-slaughter handling for dogs.

\section{Data analyses}

The data collected were analyzed using descriptive statistics such as percentages and line graph of Microsoft Excel spread sheet 2007.

\section{Results and Discussion}

The data showed that of the 120 butchers interviewed, 114 (95\%) practiced the strangulation method of pre-slaughter handling. The frequency of practice for the strangulation method declined from $95-90 \%$ before increasing to $100 \%$, it undulates each day across the range of $90-100 \%$ during the study period.

The suffocation method was used by 2 of the 120 butchers with $1.7 \%$ as overall use frequency. The group frequencies were highest at $5 \%$, some group had no frequency recorded for this method.

The stunning method was utilized by 4 butchers with $3.3 \%$ as the overall frequency of use. The group frequencies were highest at $10 \%$, some recorded $5 \%$ and others no frequency (Table 1, Figure I).

That for the suffocation was $1.7 \%$ as total frequency. It is the least utilized method due to difficulty of use, but said to be effective by butchers. The stunning method had an overall frequency of $3.3 \%$, it is easy to use but may be ineffective at times (Table 2). The strangulation method of pre-slaughter handling has the highest frequency of $95 \%$ practice among butchers. The reasons given for the use of the method with $95 \%$ overall frequency by butchers, was said to be due to ease of use and effectiveness of the method. Dogs are first strangled before bleeding

\section{Data collection}

Table 1: The Frequency of Different Traditional pre-slaughter Handling Methods Used by Butchers at the "Angwan Kere" Dog Market

\begin{tabular}{|c|c|c|c|c|c|c|c|}
\hline Days & $\begin{array}{c}\text { Number of } \\
\text { Butchers }\end{array}$ & $\begin{array}{c}\text { Strangulation } \\
\text { Method }\end{array}$ & $\begin{array}{c}\text { Frequency of } \\
\text { Use (\%) }\end{array}$ & $\begin{array}{c}\text { Suffocation } \\
\text { Method }\end{array}$ & $\begin{array}{c}\text { Frequency of } \\
\text { Use (\%) }\end{array}$ & $\begin{array}{c}\text { Stunning } \\
\text { Method }\end{array}$ & $\begin{array}{c}\text { Frequency of } \\
\text { Use (\%) }\end{array}$ \\
\hline 1 & 20 & 19 & 95 & 0 & 0 & 1 & 5 \\
\hline 3 & 20 & 20 & 100 & 0 & 0 & 0 & 0 \\
\hline 4 & 20 & 19 & 95 & 1 & 5 & 0 & 0 \\
\hline 5 & 20 & 20 & 100 & 0 & 0 & 0 & 0 \\
\hline
\end{tabular}


through severing of the jugular veins. This is consistent with the report of Ehimiyein et al. (2014). Dogs are also beaten with large sticks or iron rods inside sacks and left to suffocate to death. The general belief among butchers is that the more gruesome a dog's death, the sweeter the meat would be (Elisha \& Solomon, 2008). This belief as reported by Elisha \& Solomon (2008), are inconsistent with established findings on the negative effects of stressful pre-slaughter handling of animals on meat quality (Adzitey, 2011). Dogs sold for slaughter are usually not fed, this can enhance meat quality in terms of longer shelf life due to absence of gut content contamination of carcass during evisceration, consistent with the report of Sofos et al.

(1999). Changing such belief among butchers may pose a challenge, as slaughter points for dogs are usually located in hidden areas, consistent with the findings of Ekanem et al. (2013) and the fact that dog meat consumption is regarded by many people as unethical and taboo on several grounds (Garba et al., 2013). However, only a small number $1.7 \%$ of butchers agree to the use of the suffocation method. The stunning method has 3.3\% frequency of use, which is a bit higher than that for suffocation but much lower than for the strangulation method. The low stunning frequency may be attributed to the poor outcome from the use of inappropriate stunning device (wooden staffs) by butchers. This is in contrast with the findings of Facco Silveira et al. (1998) which established that pre-slaughter stunning should render animals insensible to pain and that animals do not suffer needlessly during slaughter. In conclusion, It is evident from the study that the strangulation method, with a frequency of $95 \%$ use is the most preferred pre-slaughter handling method by dog butchers at the "Angwan Kare"(dog market) Jos, Plateau State. The stunning of animals has been proven to be the best pre-slaughter handling method. Dog butchers should be trained and taught the proper pre- slaughter stunning techniques for dogs, its role in the enhancement of meat quality, shelf life and contribution to animal welfare through the relief of pain, fear and suffering.

\section{Acknowledgement}

The authors wish to acknowledge all the butchers that participated in this study at the Agwan Kare dog market Jos. We thank them for their patience, support and co-operation during the study.

\section{Conflicts of Interest}

The authors declare they have no conflict of interest.

\section{References}

Adzitey $F$ (2011). Effect of preslaughter animal handling on carcass and meat quality. International Food Research Journal. 18(2):485-491.

Aiyedun JO \& Olugasa BO (2012). Identification and analysis of dog use, management practices and implications for rabies control in llorin, Nigeria. Sokoto Journal of Veterinary Sciences, 10(2): 1-6.

Douglas M (2009). The Home of the Blizzard. In: Geoffrey C and David W (Eds). The Project Gutenberg

EBook. 
http://www.gutenberg.org/files/6137/6137 -h/6137- h.htm\#2HCH0013, retrieved on 17-10-2013.

Ehimiyein A, Audu S \& Ehimiyein, I (2014). Role of dog trading and slaughter for meat in rabies epidemiology with special reference to Nigeria-A review. Journal of Experimental Biology and Agricultural Sciences, 2 (2): 131136.

Ekanem EE, Eyong KI, Philip-Ephraim EE, Eyong ME, Adams EB \& Asindi AA (2013). Stray dog trade fuelled by dog meat consumption as a risk factor for rabies infection in Calabar, southern Nigeria. African Health Sciences, 13 (4): 1170- 1173.

Elisha IL \& Solomon P (2008). Cruelty to dogs: A survey of responses in Bukuru Metropolis, Jos, Nigeria. Nigerian Veterinary Journal, 29 (1): 63-67.

Facco Silveira, ET, Silviera NFA \& Beraquet NJ (1998). The influence of stunning techniques on some quality aspects of pig meat. International Congress of Meat Science and Technology (Barcelona, Spain), 44:1072-1073.

Garba A, Dzikwi AA, Okewole PA, Chitunya-Wilson $B B$, Tirmidhi $A B$, Kazeem $H M$ \& Umoh JU (2013). Evaluation of dog slaughter and consumption practices related to the control of rabies in Nigeria. Journal of Experimental Biology and Agricultural Sciences, 1 (2S): 125-130.

Manteca X (1998). Neurophysiological assessment of welfare. Meat Science, 49, S205-S218
Mao C (2010). Tribal Naga Dog meat delicacy. Demotix

http://www.demotix.com/news/302632/tri

bal-naga-dog-meat-delicacy retrieved on 17-10-2013.

Michele B (2017). Fight dog meat. https://fightdogmeat.com/2017/07/Nigeria , retrieved 17-07-2017.

Murray S (2007). Dog's dinners prove popular in Nigeria. $\quad B B C \quad N e w s$, http://news.bbc.co.uk/1/hi/world/africa/64 19041.stm, retrieved on 17/10/2007

Rupert WH (2002). China's taste for the exotic. BBC News

http://news.bbc.co.uk/2/hi/programmes/fr om_our_own_corresp ondent/2074073.stm, retrieved on 17-102013.

Shepherd J (2012.) All About Indonesian Dog Meat. Buzz Feed Staff. http://www.buzzfeed.com/expresident/allabout-indonesian-dog-meat retrieved on 17-10-2013.

Simmons FJ (1994). Eat Not This Flesh: Food Avoidances from Prehistory to Present, second edition. University of Wisconsin Press. Pp 229 -240.

Sofos JN, SL.Kochevar SL, Bellinger GR, Buege DR, Hancock DD, Ingham SC, Morgan JB \& GC Smith (1999). Sources and Extent of Microbiological Contamination of Beef Carcass in seven US Slaughtering Plants, Journal of Food Protection, 62 (2): 14. 